\title{
EMG Pattern Analysis for A Hemiplegic Boy While Using VR-Glasses
}

\author{
Michael Jung1*, Ronald Burger ${ }^{2}$ and Jennifer Höning ${ }^{3}$ \\ ${ }^{1}$ SRH University of Applied Sciences Heidelberg, Germany \\ ${ }^{2}$ BRSU University of Applied Sciences Bonn-Rhein-Sieg, Germany \\ ${ }^{3}$ Fresenius University of Applied Sciences Frankfurt, Germany \\ *Corresponding author: Michael Jung,SRH University of Applied Sciences Heidelberg, Germany

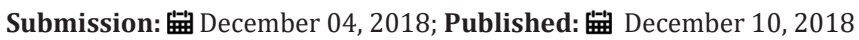

\begin{abstract}
This is a case report about a 12-year old boy with a spastic hemiplegia receiving therapy via VR glasses. The researchers try to demonstrate that the use of VR glasses showing 3-dimensional video sequences can stimulate the affected side of the brain comparable to mirror therapy. Therefore, the researchers videotaped ambidextrous 3-dimensional video sequences (actions) in an ego-perspective. An EMG pattern analysis demonstrate a tone influencing effect of the VR-glasses on this boy`s spastic upper limb. These first results lead to a greater RCT in this field.
\end{abstract}

Keywords: Ambidextrous actions; Ego perspective; EMG pattern analysis; Single case study; VR glasses

\section{Introduction}

Mirror therapy for hemiplegic children is well known, widely used and effective [1,2]. Based on this therapy the authors started a similar study with VR-glasses. Under the use of VR-glasses children with hemiparesis watching three-dimensional videos (3D) showing ambidextrous activities of daily living. Because of the great prompt character using a new mobile phone and the VRglasses the researches wanted better therapy compliance in this young intervention group. The hypothesis of the research team is that a 3-D-video has much more impact than mirror therapy.

\section{Background}

If mirror therapy uses an illusion created by the mirror, in this study the researchers use an illusion created by the 3-D-video sequences. While the mirror is placed on a table in the center of the child's body, now the VR-glasses are onto their head and it will be a greater illusion because of the impressing 3-D-technique and the ego perspective. The assumption of the researcher was that VR-therapy has the same effect as mirror therapy: movement observation should recruit the same neural structures as the execution of the movement itself [3]. This additional therapeutic application should support the affected hemisphere in cortical reorganization and improve motor function [4]. The authors transfer the assumption that by watching the ambidextrous movements in the video important motor areas are activated in the affected hemisphere, which could normally only be activated by voluntary movements of the hemiparetic extremity itself [5]. With an incidence of approximately 3-5 and 1.6:100.000 hemiparesis because of an ischemic stroke in children and adolescents under 16 years is an important field for therapy [6,7]. Strokes in newborns, like our participant, have an incidence of 1: 2.500-4.000. These children often show a developmental disregard on the affected limb. Therefore, the researchers were looking for an important triggering object-related ambidextrous action. They decided for table soccer, flipper, eating and cycling. This single case study was carried out, because so far there is close to no evidence for children with hemiparesis and the use of VR-glasses.

\section{Objectives}

In this study the investigators analyses the EMG patterns in a hemiplegic boy while using VR-glasses.

This leads to the following questions:

a) Is there a difference in the EMG patterns before and during VR use?

b) Is there a difference in the EMG patterns between watching 2-D-photos with ambidextrous situations and 3-D VR sequences?

c) Are the differences in the EMG patterns between the three situations?

d) Is there a different in the EMG patterns between the left and the right arm?

\section{Method}

This study was approved by the ethics committee of Fresenius University of Applied Sciences Frankfurt (Germany). The Patients were recruited in cooperation with the Department 
of Neuropediatric at the Goethe-University Frankfurt and the Neurodevelopmental Center Frankfurt-Höchst (SPZ). They had to meet the following inclusion criteria shown in Table 1.

Table 1: Inclusion and exclusion criteria.

\begin{tabular}{|c|c|}
\hline Inclusion Criteria & Exclusion Criteria \\
\hline $\begin{array}{c}\text { Children and adoles- } \\
\text { cents 6 -19 years of age }\end{array}$ & $\begin{array}{c}\text { Children younger than } 6 \text { and adolescents } \\
\text { older than } 19 \text { years }\end{array}$ \\
\hline Hemiparesis; G81.1 & \\
\hline $\begin{array}{c}\text { Good knowledge of } \\
\text { German }\end{array}$ & \\
\hline $\begin{array}{c}\text { Written informed } \\
\text { consent }\end{array}$ & \\
\hline
\end{tabular}

A twelve years old boy with hemiparesis left took place in this single case study. Written informed consent was obtained and he has no experience with VR-glasses before. The boy was sitting at a table, both hands on the tabletop. EMG of three muscles on the right and the left arm were recorded at $2000 \mathrm{~Hz}$ using bipolar surface electrodes and single differential amplifiers (biovision) for $2 \mathrm{~min}$. The following muscles were considered: M. deltoideus, M. biceps brachii, M. triceps brachii and the forearm flexors. The signals were rectified and smoothed using the root mean square (RMS) with a $200 \mathrm{~ms}$ window. To analyze the treatments we use the average, the standard deviation and the median frequency of the signal. Measurement time 1 was at rest without intervention, measurement time 2 was under 2-D-stimulation and finally measurement time 3 was under 3-D-stimulation. A 3-D movement sequence is presented via virtual reality glasses (VR glasses) to the boy in such a way that he believes that his affected limb would be actively involved. Therefor all videos were recorded in the so called "ego perspective" (Figure 1).

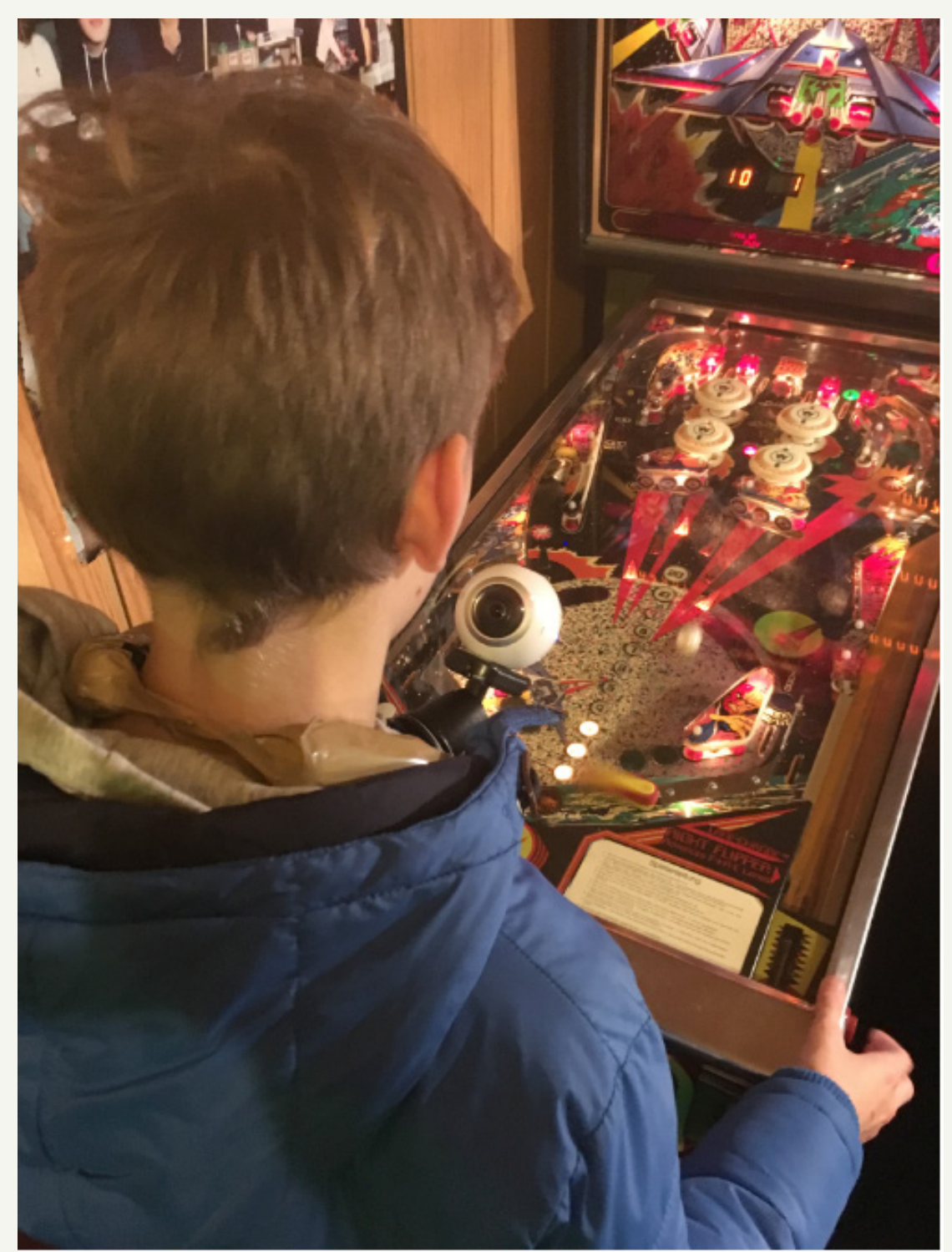

Figure 1: Recording the ego perspective. 
Videos sequences of five minutes each were shown to the boy because Laver et al. [8] recommended not exceeding a treatment time of 20 minutes.

\section{Results \& Discussion}

In general: In the left - right comparison, the relative values are comparable, so that it can be seen his deltoid muscle compensates for the activities on the affected arm. On the affected arm: Both interventions (2-D and 3-D) reduce the basal activity of the musculature compared to the resting measurement (Figure 2).

The 3-D videos of the VR glasses slightly increase the values compared to the 2-D image measurement (systematic, not clear). Due to the higher resting activity of the hemiplegic arm compared to the unaffected arm, it can be assumed that the abnormally high resting tone is lowered by the 2-D images and the 3 -D videos with the VR glasses (except on the triceps muscle). The therapeutic use of VR glasses seems to have a tone influencing effect on hypertonic muscles [9-15]. It must be mentioned that the boy was very excited because he was allowed to practice with the VR glasses. This has certainly increased his resting tone. Our first assumption that lesscontrolled muscles become more active could not be confirmed with this EMG application. Here, it has been shown that spastic muscles (e.g. biceps brachii muscle) relax from the tone.

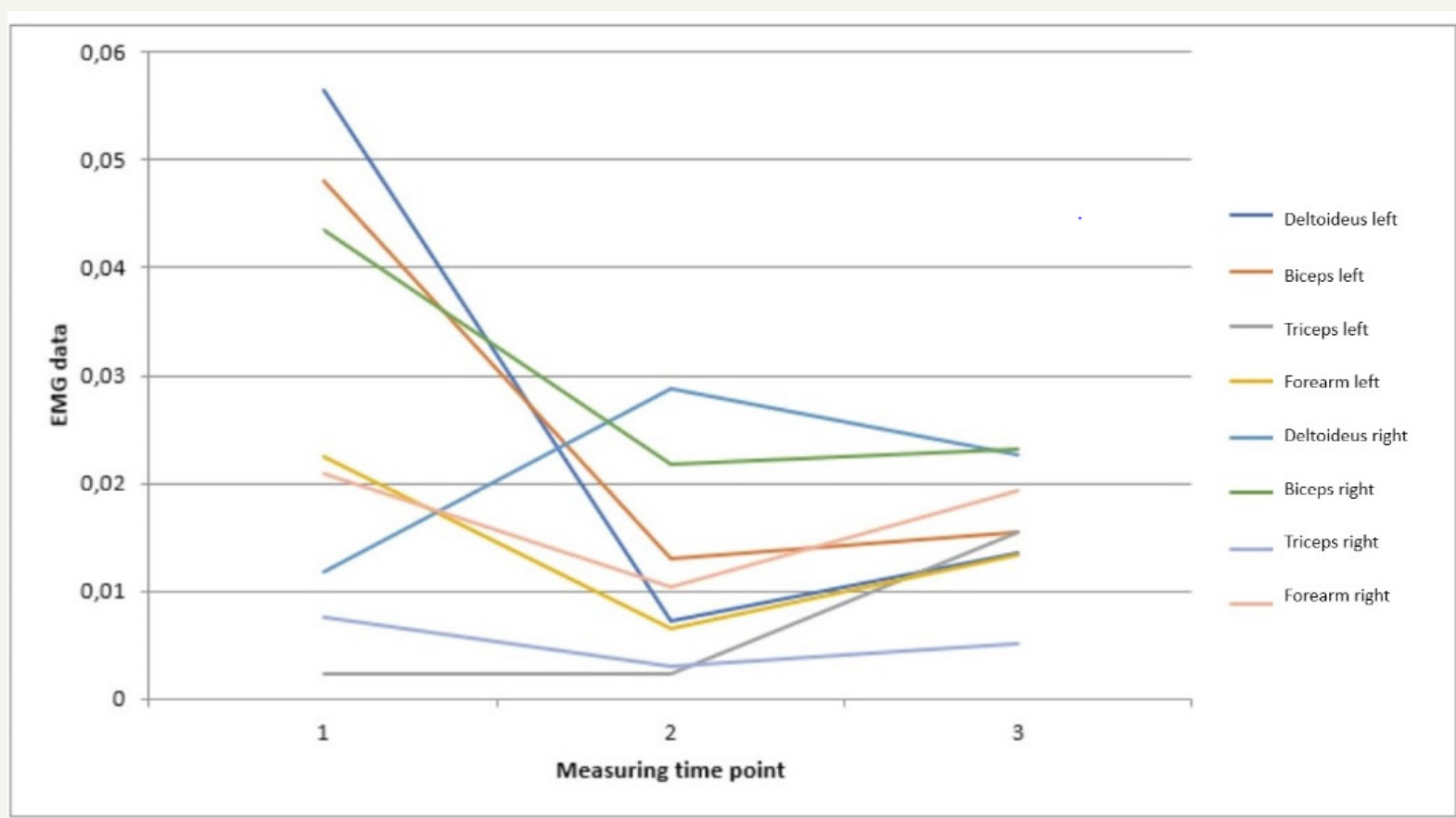

Figure 2: EMG diagram.

But this relaxation of the tone can also be caused by the lessening of the excitement [16-21].

\section{Perspective}

The use of VR glasses with therapy-supporting threedimensional video sequences is an "en vogue" medium. Considering possible side effects, the investigators have observed initial interesting effects on muscle tone and activity in a boy with spastic hemiparesis. This is now being pursued in a larger RCT.

\section{Conflict of Interest}

The authors declare no conflict of interests.

\section{References}

1. Gygax M, Schneider P, Newman C (2011) Mirror therapy in children with hemiplegia: a pilot study. Developmental Medicine \& Child Neurology 53: 473-476.

2. Jung M, Wachter S, Tomczak M (2017) Effekte der Spiegeltherapie bei einem jungen mit spastischer Hemiparese. Kinder- und Jugendmedizin 17: 164-169.

3. Buccino G, Binkofski F, Riggio L (2004) The mirror neuron system and action recognition. Brain and Language 89(2): 370-376.

4. Michielsen M, Selles R, van der Geest J, Eckhardt M, Yavuzer G, et al. (2011) Motor recovery and cortical reorganization after mirror therapy in chronic stroke patients: a phase ii randomized controlled trial. Neurorehabilitation \& Neural Repair 25(3): 223-233.

5. Rothgangel A (2008) Spiegeltherapie-mehr als nur eine visuelle Illusion? pt_Zeitschrift für Physiotherapeuten 60: 1243-1249

6. Steinlin M, Wehrli EB (2009) The ischemic vascular event in pediatrics. When to think about it - what to do. Paediatrica 20: 22-26.

7. Mallick AA, Ganesan V, Kirkham F, Fallon P, Hedderly T, et al. (2014) Childhood arterial ischaemic stroke incidence, presenting features, and risk factors: a prospective population-based study. Lancet Neurol 13: 35-43.

8. Laver KE, George S, Thomas S, Deutsch JE, Crotty M (2015) Virtual reality for stroke rehabilitation. Cochrane Database of Systematic Reviews (2): CD008349, doi:10.1002/14651858.CD008349.pub3

9. Bauder H, Taub E, Miltner W (2001) Behandlung motorischer störungen nach schlaganfall. Göttingen: Hogrefe Verlag.

10. Deluca S, Echols K, Law C, Ramey L (2006) Intensive pediatric constraint induced therapy for children with cerebral palsy: Randomized, controlled crossover trial. Journal of Child Neurology 21(11): 931-938. 
11. Dohle C, Morkisch N, Lommack R, Kadow L (2011) Spiegeltherapie. Neuroreha 4: 184-190.

12. Elbert T, Rockstroh B (2006) Kortikale reorganisation. In: Karnath HO, Thier P (Eds.), Neuropsychologie. Heidelberg: Springer Verlag 2006: 643-651

13. Hamzei F, Binkofski F, Buccino G, Ertelt D, Hauptmann B, et al. (2008) Evidenzbasierte neuroreha. Stuttgart: Thieme Verlag.

14. Jung M, Höning J (2017) Therapy accompanying use of VR-glasses in hemiparetic children and adolescents. J Nov Physiother Phys Rehabil 4(3): 87-89.

15. Liepert J, Miltner WR, Bauder H, Sommer M, Dettmers C, et al. (1998) Motor cortex plasticity during constraint-induced movement therapy in stroke patients. Neuroscience Letters 250(1): 5-8.

16. Platz T, van Kaick S, Moller L, Freund S, Winter T, et al. (2005) Veränderungen des motorischen Kortex sind für motorische Erholung nach Schlaganfall relevant. Journal of Neurology 252: 1363-1371.
17. Rose FD, Attree EA, Brooks BM (2000) Training in a virtual environment: transfer to real world tasks and equivalence to real task training. Ergonomics 43(4): 494-511.

18. Small S, Buccino G, Solodkin A (2012) The mirror neuron system and treatment of stroke. Developmental Psychobiology 54: 293-310.

19. Todorov E, Shadmer R, Bizzi E (1997) Augmented feedback presented in a virtual environment accelerates learning of a difficult motor task. Journal of Motor Behavior 29(2): 147-158.

20. Ward NS, Brown MM, Thompson AJ, Frackowiak RS (2003) Neural correlates of outcome after stroke: a cross-sectional fMRI study. Brain 126: $1430-1448$.

21. Yavuzer G, Selles R, Sezer N, Sütbeyaz S, Bussmann JB, et al. (2008) Mirror therapy improves hand function in subacute stroke: A randomized controlled trial. Arch Phys Med Rehabil 89: 393-398.
Creative Commons Attribution 4.0 International License

For possible submissions Click Here

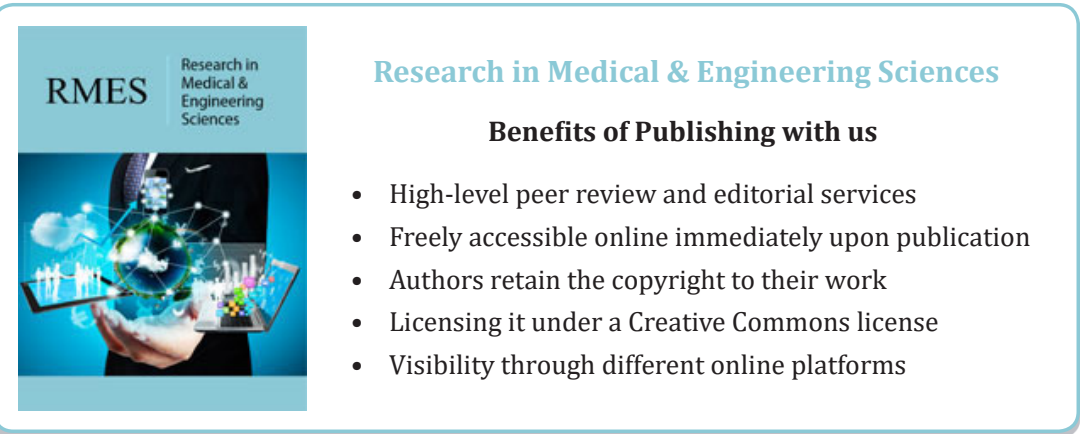

